\title{
Comparison of walking performance over the first 2 minutes and the full 6 minutes of the Six-Minute Walk Test
}

\author{
Richard W Bohannon ${ }^{1}$, Deborah Bubela ${ }^{1 *}$, Susan Magasi ${ }^{2,6}$, Heather McCreath ${ }^{3}$, Ying-Chih Wang ${ }^{4}$, David Reuben ${ }^{3}$, \\ William Z Rymer ${ }^{5}$ and Richard Gershon ${ }^{2}$
}

\begin{abstract}
Background: Although the Six-Minute Walk Test (6MWT), as recommended by the American Thoracic Society, is widely used as a measure of functional endurance, it may not be applicable in some settings and populations. We sought to examine, therefore, performance over the first 2 minutes and the full 6 minutes of the 6MWT. Specifically, we investigated completion rates, distances walked, test-retest reliability, and the relationship between distances walked over the first 2 and the full 6 minutes of the $6 \mathrm{MWT}$.
\end{abstract}

Methods: Community-dwelling children and adults age $3-85$ years $(n=337)$ were asked to walk back and forth on a 15.24 meter ( $50 \mathrm{ft}$ ) course as far as possible without running over a 6 minute period. Test completion and the distance covered by the participants at 2 and 6 minutes were documented. The reliability of distances covered at 2 and 6 minutes was determined by retesting a subsample of 54 participants 6 to 10 days later. The relationship between distances covered at 2 and 6 minutes was determined for the 330 participants completing the $6 \mathrm{MWT}$.

Results: All 337 participants completed at least 2 minutes of walking, but 7 children less than 5 years of age ceased walking before 6 minutes had elapsed. For the remaining 330 participants the mean distance walked was 186 meters at 2 minutes and 543 meters at 6 minutes. The distances covered at 2 and 6 minutes were reliable between sessions (intraclass correlation coefficients $=0.888$ and 0.917, respectively). The distances covered over 2 and 6 minutes were highly correlated $(r=0.968)$.

Conclusions: The completion rate, values obtained, test-retest reliability, and relationship of the distances walked in 2 and 6 minutes support documentation of 2 minute distance during the 6MWT. The findings also provide support for use of a Two-Minute Walk Test as the endurance component in the Motor Battery of the NIH Toolbox.

\section{Background}

Functional endurance is necessary for individuals to live independently without accommodation in community settings [1]. Walk tests, in which the distance covered over a period of time is documented, have been used since at least the 1970s to quantify functional endurance [2]. Though most widely used among patients with pulmonary [2-4] or cardiac [5,6] diagnoses, walk tests have also been employed for patients with neurologic problems $[7,8]$, amputations [9], circulatory insufficiency [10], orthopedic conditions [11] and renal [12] or liver [13] disease.

\footnotetext{
*Correspondence: deborah.bubela@uconn.edu

'Physical Therapy Program, Department of Kinesiology, Neag School of Education, University of Connecticut, Storrs, CT 06269-2101, USA Full list of author information is available at the end of the article
}

The tests have been utilized with community-dwelling children $[14,15]$ and adults $[16,17]$ as well. Walk tests described in the literature range in duration from 1 to 12 minutes $[2,3,8]$, but the Six-Minute Walk Test (6MWT) is probably the most frequently used. The American Thoracic Society has recommended the 6MWT and published guidelines for its administration [18].

Broad use and the American Thoracic Society's recommendation notwithstanding, the duration of the 6MWT renders its use impracticable in busy settings- particularly if numerous individuals need to be tested over a limited time span. Moreover, some individuals are unable or unwilling to complete the $6 \mathrm{MWT}$, even with allowable standing rests [19-21], resulting in null values. This fact has led to the use and recommendation of shorter 
duration walk tests- most notably the Two-Minute Walk Test (2MWT) $[19,20,22]$. To date, the completion of $2 \mathrm{mi}-$ nutes of walking and the distance walked over 2 minutes has not been documented over the 3 to 85 year age span. Good intra-rater and interrater reliability have been described for distances achieved during 2MWTs, at least for older adults residing in long-term care [20] and patients with stroke [7]. However, the reliability of distances covered during the first 2 minutes of the 6MWT has not been described. Distances traversed during a 2MWT and 6MWT have been shown to be highly correlated $(\mathrm{r}=$ $0.930-0.997)[4,7,20,23]$, but the relationship between the distance walked during the first 2 minutes of the $6 \mathrm{MWT}$ and the distance covered over the full course of the $6 \mathrm{MWT}$ is not established. If the completion rate for 2 minutes of walking surpasses that of 6 minutes of walking and if the distance covered during the first 2 minutes of the 6MWT is reliable and strongly related to the 6MWT distance, measurement of the distance covered in the first 2 minutes might be justified and perhaps considered as a substitute for the 6MWT distance. The purpose of this study, therefore, was to describe completion rates and distance walked, determine the test-retest reliability for the distances walked, and ascertain the relationship between the distance walked in the first 2 minutes and full 6 minutes of the 6MWT.

\section{Methods}

This investigation was part of the validation phase of the Motor Domain of the National Institutes of Health (NIH) Toolbox for the Assessment of Neurological and Behavioral Function (NIH Toolbox) study [24]. It included data gathered from convenience samples tested at 3 participating sites (University of Connecticut, Rehabilitation Institute of Chicago, and University of California Los Angeles). The institutional review boards from each site approved the study. All participants or their legal guardians provided written informed consent before testing. Participants were 3-85 years of age. Inclusion required that participants were fluent in English, were able to walk without use of an assistive device, and had no heart, vascular, lung, or bone/joint problems that precluded their ability to walk independently.

Prior to obtaining candidate measures for the $\mathrm{NIH}$ Toolbox, basic demographic (age, gender), anthropometric (height, weight [body mass index]), and health status information was obtained along with baseline heart-rate and blood pressure measurements. Thereafter, in random order, participants completed the 6MWT as either the first or last task of the larger battery of tests. Participants were asked to walk as far as possible without running for 6 minutes. They walked on a flat, hard and straight 15.24 meter (50 foot) course marked on both ends with traffic cones. At 1 minute intervals they were told that they were "doing well" or to "keep up the good work" and informed of the time remaining. Participants were allowed to take a standing rest if they chose to do so at any point, but were asked to resume walking if and when possible until the 6 minute period had elapsed. The distances covered in 2 and 6 minutes were documented. A subset of 54 participants distributed across age and sex strata repeated the walk tests within a 6-10 day interval to examine test-retest reliability of the measures. These participants were the first who agreed to return for retesting.

Performance over the course of the 6MWT and across the age-span was first described by noting the number of participants not completing the 6MWT. For individuals completing the 6MWT descriptive statistics (range, mean, standard deviation, and confidence intervals) were calculated for the distances walked in 2 and 6 minutes. Intraclass correlation coefficients (ICCs) were used to describe the reliability of the distances walked in 2 and 6 minutes. A Pearson correlation and linear regression were used to determine the relationship between the distances covered over the first 2 and the total 6 minutes of the 6MWT. Statistical analyses were completed using SPSS 15.0 with an alpha level of 0.05 .

\section{Results}

Table 1 summarizes demographic and other nonperformance data describing the 330 participants who completed the $6 \mathrm{MWT}$. Approximately $55 \%$ of the participants were female and about 35\% identified their race as other than White. Most participants reported their health to be excellent (49\%) or very good (36\%).

Seven of 337 individuals (2.1\%) who enrolled in the study did not complete the 6MWT. All 7 were less than 5 years old. One $(0.3 \%)$ of the 7 refused to attempt the task. The other $6(1.8 \%)$ walked at least 2 minutes but stopped before 6-minutes had elapsed and declined to resume walking for nonphysical reasons (e.g., averted attention).

For the 330 individuals completing the 6MWT, only 1 required a standing rest stop. The distance walked over the course of 2 minutes was $186 \pm 34$ (91-290) meters. Over the full 6 minutes the distance walked was $543 \pm$ 102 (258-823) meters. Individual performance varied considerably (Figure 1). Only participants aged less than 7 years or more than 74 years walked 135 meters or less in 2 minutes $(\mathrm{n}=23)$ or 396 meters or less in 6 minutes $(\mathrm{n}=22)$ (Figure 2). Excellent test-retest reliability was demonstrated for the distances covered over the first 2 minutes (ICC $=0.888[0.814-=0.933]$ ) and the full 6 minutes (ICC $=0.917[0.862-0.951]$ ) of the 6MWT. The distances covered over 2 and 6 minutes were correlated highly $(\mathrm{r}=0.968, \mathrm{p}<0.0001)$. The linear regression 
Table 1 Number (\%) of participants completing walk task by demographic characteristics

\begin{tabular}{lc}
\hline Variable & N (\%) \\
\hline Site* $^{*}$ & $137(41.5)$ \\
University of Connecticut & $116(35.2)$ \\
Rehabilitation Institute of Chicago & $77(23.3)$ \\
$\quad$ University of California, Los Angeles & $330(100)$ \\
Total & \\
Gender & $180(54.5)$ \\
Female & $150(45.5)$ \\
Male & \\
Age (yrs) strata per study design* & $58(17.6)$ \\
3-6 & $78(23.6)$ \\
7-13 & $33(10.0)$ \\
14-20 & $100(30.3)$ \\
21-65 & $61(18.5)$ \\
$66-85$ & $37(11.2)$ \\
Hispanic or Latino & \\
Race & $211(63.9)$ \\
White & $50(15.2)$ \\
Asian & $29(8.8)$ \\
Black & $40(12.1)$ \\
\hline Other &
\end{tabular}

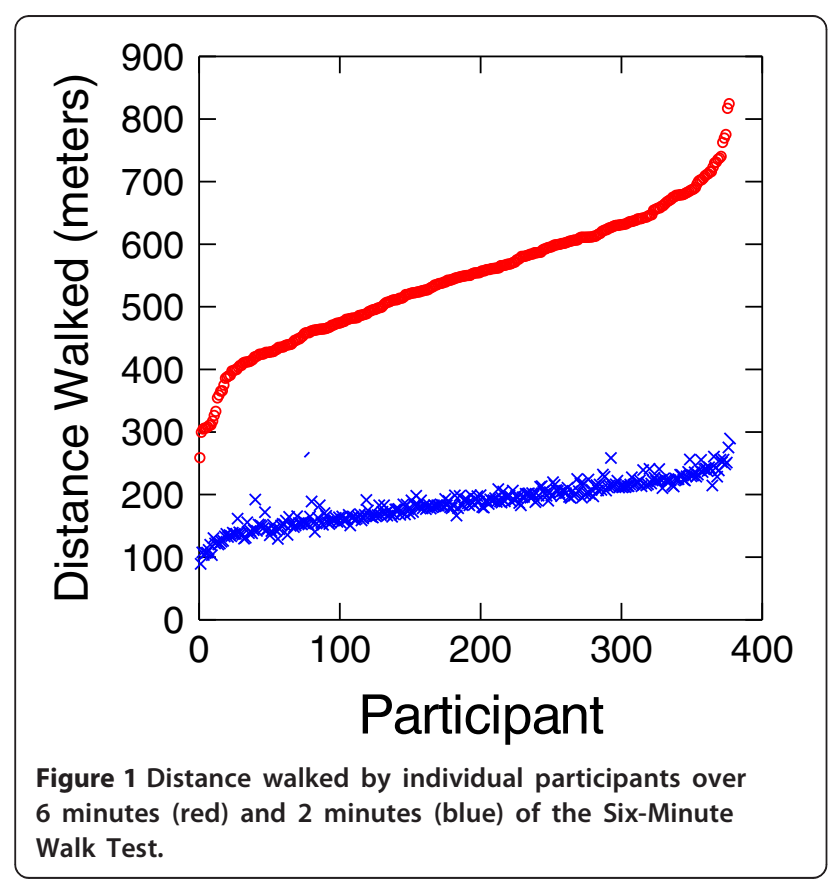

equation describing the relationship was: 6MWT distance (meters) $=27$ meters $+2.87 * 2$ minute distance (meters).

\section{Discussion}

Timed walk tests are commonly used to measure the functional endurance of diverse populations [1-23]. Among such tests, the 6MWT, as recommended by the American Thoracic Society, is probably the most widely used. This led to its inclusion in the validation phase of the $\mathrm{NIH}$ Toolbox project [24]. In the validation phase we were particularly interested in the rate of test completion, test performance, test-retest reliability, and the degree to which the distances walked over earlier minutes of the test were reflective of the distance covered over the full 6-minute duration of the 6MWT.

The completion rate we observed for the 6MWT was 97.9\%. Only individuals less than 5 years old failed to complete the test. The completion rate among the children we tested was less than the $100 \%$ reported by Lammers et al. for 4-11 year old children [14] and greater than the 82.5\% reported by Geiger et al. for boys and girls 3-18 years of age [21]. Among a subset of children 3-5 years of age in their study, Geiger et al. reported a "response rate" of only $39 \%$, though they did not operationalize "response rate". All of the community-dwelling older adults we studied completed the 6MWT. Our sample, therefore, was more able than that of Brooks et al. [19]. Of their older adults, who were undergoing rehabilitation, only 1 of 8 was able to walk for 6 minutes. As a consequence they abandoned further testing with the $6 \mathrm{MWT}$ and resorted to using a 2MWT. Fifty of 52 older adults tested by Brooks et al. were able to complete a $2 \mathrm{MWT}$. Gijbels et al., who tested patients with multiple sclerosis, have suggested that "the last 4-minute period of the 6MWT seems redundant" [23]. Together these findings support the measurement of distance walked over 2 minutes, whether it be the first 2 minutes of a $6 \mathrm{MWT}$ or a $2 \mathrm{MWT}$. By capturing the distance walked over 2 minutes null values might be avoided in clinical documentation and research trials.

We documented the distances walked by our convenience sample of participants over 6 minutes and over the first 2 minutes of the 6MWT. We used a back-and-forth distance of 15.2 meters rather than the 30.5 meter distance recommended by the American Thoracic Society [18] as we judged it to be more ecologically generalizable. Although a greater frequency of turns has the potential to suppress the distance walked over time [25], the distances we report for 6 minutes appear to be relatively comparable to those reported by others testing able-bodied children and adults [14,26-29]. Specifically, the mean distance walked by children (3-11 years) in our study was 510 meters compared to $470 \pm 59$ meters in the study of Lammers et al. [14]. The median distance covered by adults ( 40 or more years) in our study was 

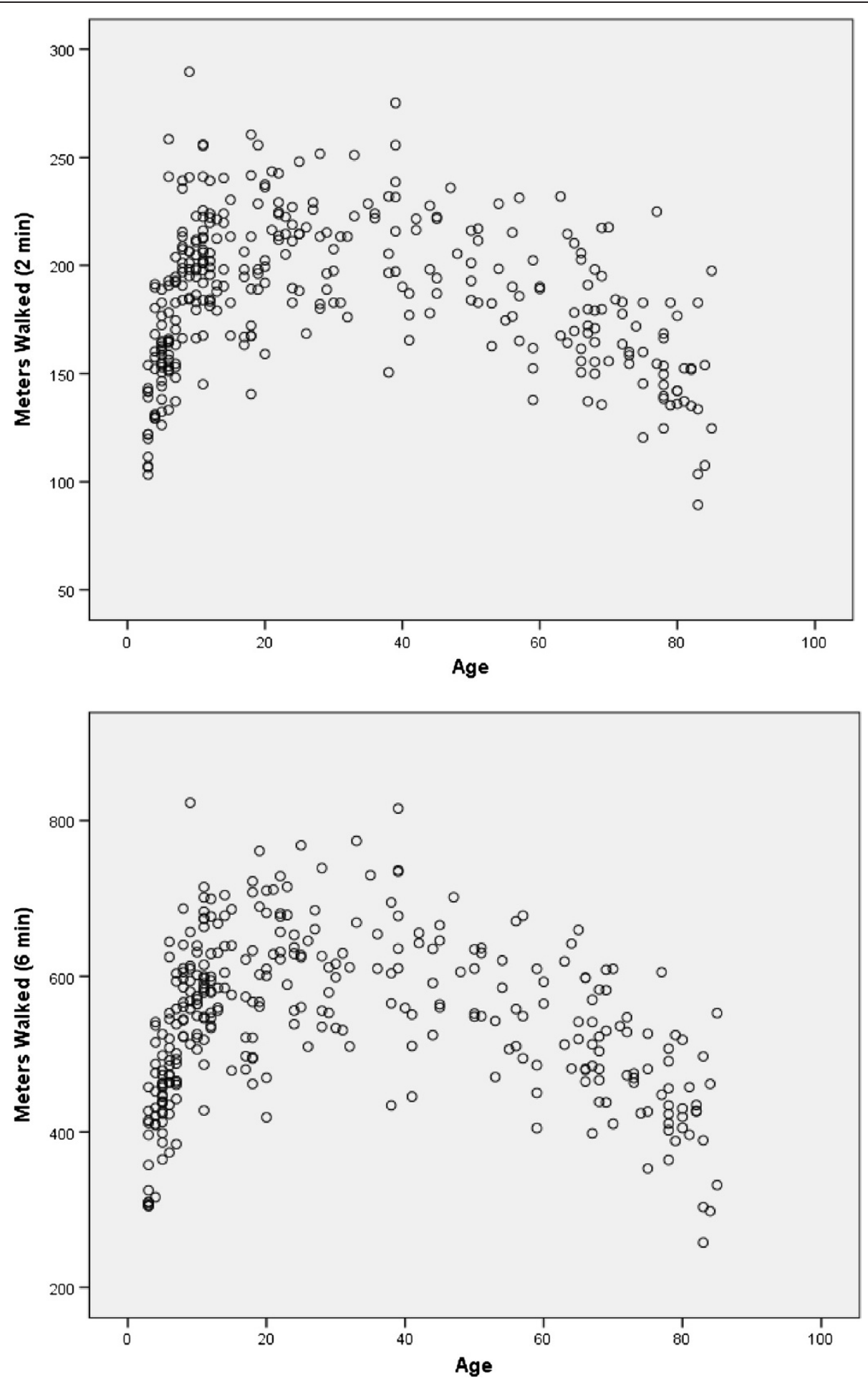

Figure 2 Scatterplots showing the relationship between age and distance walked in 2 minutes (top) and 6 minutes (bottom) of the Six-Minute Walk Test.

512 meters compared to 527 meters in the study of Enright and Sherrill [29]. Regarding the distance walked by our participants in the first 2 minutes of the $6 \mathrm{MWT}$ (186 meters), it far exceeded mean 2MWT distances for older adults in long-term care [20], patients with lowerlimb amputations [9], patients undergoing cardiac surgery [22], and patients with stroke [7]. Providing additional perspective, the mean distance our participants 
walked in the first 2 minutes of the 6MWT also exceeded the mean distances required to traverse a post office (52.0 meters), bank (57.1 meters), or medical office building (65.8 meters); the mean distance covered over the full 6 minutes exceeded the mean distances needed to traverse a pharmacy (206.3 meters), department store (345.9 meters), or grocery store (380.6 meters) [30]. So even if we do not consider our 2-minute or 6-minute distances to be normative, they are comparable to data obtained from other community-dwelling individuals, greater than data obtained from patient groups, and ecologically relevant.

By measuring performance at 2 and 6 minutes of the $6 \mathrm{MWT}$ on 2 occasions, we were able to examine the reliability of distances covered at both times. While the ICC for 6 minutes was of greater magnitude than the ICC for 2 minutes, both are indicative of good reliability and fall within the confidence intervals of one another. Moreover, the ICCs for 2 minutes are within the range of those reported for patients with stroke $(\mathrm{ICC}=0.85)$ [7] and for older adults in long-term care (0.94 and 0.95) [20].

Although we did not separately examine participants using a $2 \mathrm{MWT}$ and 6MWT, the correlation between the distances walked at 2 and 6 minutes of the 6MWT (0.968) is similar to correlations reported by researchers comparing 2MWT and 6MWT performance among older adults in long-term care (0.930) [20], and patients with multiple sclerosis (0.980) [23], stroke (0.997) [7], and chronic obstructive pulmonary disease (0.937) [4]. Together, these findings demonstrate that the distance walked in 2 minutes is a valid indicator of the distance covered in 6 minutes, whether the 2 minute distance is obtained from a $6 \mathrm{MWT}$ or a separate $2 \mathrm{MWT}$.

This study had several limitations. First a convenience sample of relatively healthy community-dwelling individuals was used. A population-based sample might yield different completion rates, reliability coefficients, and relationships between distances walked. Patients with limited aerobic capacity or pain might also demonstrate lower completion rates. Depending on the frequency, timing, and duration of standing rests, reliability and correlations between distances walked at 2 and 6 minutes could be depressed relative to those we found. Our study provides no indication of the relative discriminant or predictive validity of the distance walked in 2 versus 6 minutes of the 6MWT. Second, we only examined 2-minute walk distance in the context of a 6MWT. The comparability of distance walked in a $2 \mathrm{MWT}$ in our sample is therefore unknown. Individuals may walk faster if they realize they won't have to walk another 4 minutes. Third, though our sample was relatively large, we considered it to be too small to perform subgroup analysis on specific strata (e.g., girls $3-5$ years). Finally, we did not measure oxygen consumption, heart rate or perceived exertion over the course of the 6MWT. While doing so is beyond the scope of the $\mathrm{NIH}$ Toolbox project, such measures can be informative in as to specifics over the course of 6 minutes. Motl et al., for example, measured oxygen consumption at 30 second intervals of the 6MWT and found that steady-state aerobic metabolism was not reached until 3 minutes of walking were completed in patients with multiple sclerosis [31].

Future research will involve the collection of normative data for the 2MWT across the age-span. That data will then be used as a benchmark for various communitydwelling and patient groups.

\section{Conclusions}

Based on completion rates, distances walked, reliability and the high correlation between the distance walked in 2 and 6 minutes, the distance walked over 2 minutes can be considered to be a legitimate alternative to the distance walked over 6 minutes for indicating functional endurance among relatively healthy community-dwelling individuals. Even if the 6MWT is used, it may be useful to document 2-minute walk distance so that useful information is still obtained from individuals unable to complete the full 6MWT. The 2MWT will be used as the measure of functional endurance in the norming phase of the NIH Toolbox project.

\section{Competing interests}

None of the authors have any competing financial or non-financial competing interests relating to the manuscript or the content of this manuscript.

\section{Authors' contributions}

$\mathrm{RB}$ and $\mathrm{DB}$ collected and analyzed data and drafted the manuscript. SM, HM, and YW developed protocol, collected data and contributed input to the manuscript. DR, WZR, and RG conceived of the large scale NIH Toolbox study and participated in the design and coordination of the research efforts. All authors read and approved the final manuscript.

\section{Acknowledgements}

Jennifer Beaumont for statistical support and analysis; Phoebe Block, Jessica Crocker, Daisy Escobar, Michael Jesselson, Caroline Marchand, Aaron Morales, Noemi Niera, and Katherine Taft for data collection assistance; Suzann Campbell, Christine Chen, Jack Guralnik, Mark Hallett, Jane Clark, Allen Heinemann, William Evans, Dallas Anderson, Diana Damiano, Marjorie Garvey, Elizabeth Moberg-Wolff for expert consultation; and Edward Wang for early leadership was critical to domain development.

\section{Funding}

This study is funded in whole or in part with Federal funds from the Blueprint for Neuroscience Research, National Institutes of Health under Contract No. HHS-N-260-2006-00007-C and the UCLA Claude Pepper Older Americans Independence Center funded by the National Institute on Aging (5P30AG028748) (Drs. Reuben and McCreath).

\section{Author details}

'Physical Therapy Program, Department of Kinesiology, Neag School of Education, University of Connecticut, Storrs, CT 06269-2101, USA. ${ }^{2}$ Department of Medical Social Sciences, Feinberg School of Medicine, Northwestern University, Chicago, IL 60611, USA. ${ }^{3}$ Division of Geriatrics, David Geffen School of Medicine, University of California Los Angeles, Los Angeles, CA 90095, USA. ${ }^{4}$ Department of Occupational Science \& Technology, University of Wisconsin-Milwaukee, Milwaukee, WI 53201, USA. ${ }^{5}$ Sensory Motor Performance Program, Rehabilitation Institute of Chicago, 
Northwestern University, Chicago, IL 60611, USA. ${ }^{6}$ University of Illinois, Chicago, USA.

Received: 9 September 2013 Accepted: 17 April 2014 Published: 25 April 2014

\section{References}

1. Andrews AA, Chinworth SA, Bourassa M, Garvin M, Benton D, Tanner S: Update on distance and velocity requirements for community ambulation. J Geraitr Phys Ther 2010, 33:128-134.

2. McGavin CR, Gupta SP, McHardy GJR: Twelve-minute walk test for assessing disability in chronic bronchitis. Br Med J 1976, 1:822-823.

3. Butland RJA, Pang J, Gross ER, Woodcock AA, Geddes DM: Two-, six-, and 12-minute walking tests in respiratory disease. Br Med J 1982, 284:1607-1608.

4. Leung ASY, Chan KK, Sykes K, Chan KS: Reliability, validity, and responsiveness of a 2 -min walk test to assess exercise capacity of COPD patients. Chest 2006, 130:1119-1125.

5. Bittner V, Weiner DH, Yusuf S, Rogers WJ, McIntyre KM, Bangdiwala SI, Kronenberg MW, Kostis JB, Kohn RM, Guillotte M, Greenberg B, Woods PA, Bourassa MG: Prediction of mortality and morbidity with a 6-minute walk test in patients with left ventricular dysfunction. JAMA 1993, 270:1702-1707.

6. Cahalin L, Mathier MA, Semigran MJ, Dec W, DiSalvo TG: The six-minute walk test predicts peak oxygen uptake and survival in patients with advanced heart failure. Chest 1996, 110:325-332.

7. Kosak M, Smith T: Comparison of the 2-, 6-, and 12-minute walk tests in patients with stroke. J Rehabil Res Dev 2005, 42:103-108.

8. McDowell BC, Kerr C, Parkes J, Cosgrove A: Validity of 1 minute walk test for children with cerebral palsy. Dev Med Child Neurol 2005, 47:744-748.

9. Brooks D, Parsons J, Hunter JP, Devlin M, Walker J: The 2-minute walk test as a measure of functional improvement in persons with lower limb amputation. Arch Phys Med Rehabil 2001, 82:1478-1483.

10. Montgomery PS, Gardner AW: The clinical utility of a six-minute walk test in peripheral arterial occlusive disease patients. J Am Geriatr Soc 1998, 46:706-711

11. Kennedy DM, Stratford PW, Riddle DL, Hanna SE, Gollish JD: Assessing recovery and establishing prognosis following total knee arthroplasty. Phys Ther 2008, 88:22-32

12. Fitts SS, Guthrie MR: Six-minute walk by people with chronic renal failure: Assessment of effort by perceived exertion. Am J Phys Med Rehabil 1995, 74:54-58.

13. Carey EJ, Steidley DE, Agel BA, Byrne TJ, Mekeel KL, Rakela J, Vargas HE, Douglas DD: Six-minute walk distance predicts mortality in liver transplant candidates. Liver Transp/ 2010, 16:1373-1378.

14. Lammers AE, Hislop AA, Flynn Y: Haworth SG:The 6-minute walk test: normal values for children of 4-11 years of age. Arch Dis Child 2008, 93:464-468.

15. Li AM, Yin J, Yu CCW, Tsang T, So HK, Wong E, Chan D, Hon EKL, Sung R: The six-minute walk test in healthy children: reliability and validity. Eur Respir J 2005, 25:1057-1060.

16. Rikli RE, Jones $\mathrm{CJ}$ : The reliability and validity of a 6-minute walk test as a measure of physical endurance in older adults. J Aging Phys Act 1998, 6:363-375.

17. Bautmans I, Lambert M, Mets T: The six-minute walk test in community dwelling elderly: influence of health status. BMC Geriatr 2004, 4:6.

18. ATS statement: guidelines for the six-minute walk test. Am J Respir Crit Care Med 2002, 166:111-117.

19. Brooks D, Davis AM, Naglie G: The feasibility of six-minute and twominute walk tests in in-patient geriatric rehabilitation. Can J Aging 2007, 26:159-162.

20. Connelly DM, Thomas BK, Cliffe SJ, Perry WM, Smith RE: Clinical utility of the 2-minute walk test for older adults living in long-term care. Physiother Can 2009, 61:78-87.

21. Geiger R, Strasak A, Treml B, Gasser K, Kleinsasser A, Fischer V, Geiger H, Loeckinger A, Stein J: Six-Minute Walk Test in children and adolescents. J Pediatr 2007, 150:395-399.

22. Brooks D, Parsons J, Tran D, Jeng B, Gorczyca B, Newton J, Lo V, Dear C, Silaj E, Hawn T: The two-minute walk test as a measure of functional capacity in cardiac surgery patients. Arch Phys Med Rehabil 2004, 85:1525-1530.
23. Gijbels D, Eijnde BO, Feys P: Comparison of the 2-and 6-minute walk test in multiple sclerosis. Mult Scler 2011, 17:1269-1272.

24. Gershon RC, Cella D, Fox NA, Havlik RJ, Hendrie HC, Wagster MV: Assessment of neurological and behavioral function: the NIH Toolbox. Lancet Neurol 2010, 9:138-139.

25. Ng SS, Yu PC, To FP, Chung JS, Cheung TH: Effect of walkway length and turning direction on the distance covered in the 6-minute walk test among adults over 50 years of age: across-sectional study. Physiotherapy 2013, 99:63-70.

26. Li AM: Standard reference for the six-minute-walk test in healthy children aged 7 to 16 years. Am J Respir Crit Care Med 2007, 176:174-180.

27. Klepper SE, Muir N: Reference values on the 6-Minute Walk Test for children living in the United States. Pediatr Phys Ther 2011, 23:32-40.

28. Rikli RE, Jones CJ: Development and validation of a functional fitness test for community-residing older adults. J Aging Phys Act 1999, 7:129-161.

29. Enright PL, Sherrill DL: Reference equations for the six-minute walk in healthy adults. Am J Respir Crit Care Med 1998, 158:1384-1387.

30. Andrews AW, Chinworth SA, Bourassa M, Garvin M, Benton D, Tanner S: Update on distance and velocity requirements for community ambulation. J Geriatr Phys Ther 2010, 33:128-134.

31. Motl RW, Suh Y, Balantrapu S, Sandroff BM, Sosnoff JJ, Pula J, Goldman MD, Fernhall B: Evidence for the different physiological significance of the 6- and 2-minute walk tests in multiple sclerosis. BMC Neurol 2012, 12:6

doi:10.1186/1756-0500-7-269

Cite this article as: Bohannon et al:: Comparison of walking performance over the first 2 minutes and the full 6 minutes of the Six-Minute Walk Test. BMC Research Notes 2014 7:269.

\section{Submit your next manuscript to BioMed Central and take full advantage of:}

- Convenient online submission

- Thorough peer review

- No space constraints or color figure charges

- Immediate publication on acceptance

- Inclusion in PubMed, CAS, Scopus and Google Scholar

- Research which is freely available for redistribution
( Biomed Central 